\title{
Proportion of Death Certificate Only Cases and Its Related Factors, Kwangju Cancer Registry (KCR)
}

Su Jin Lee, R.N. ${ }^{1}$, Min Ho Shin, M.D. ${ }^{1}$, Sang Young Kim, M.D. ${ }^{1}$, Kyeong Soo Park, M.D. ${ }^{1}$, Young Jin Kim, M.D.', Tai Ju Hwang, M.D. ${ }^{3}$ and Jin Su Choi, M.D. ${ }^{1}$

Kwangju Cancer Registry, Gwangju, Departments of ${ }^{1}$ Preventive Medicine, ${ }^{2}$ General Surgery and ${ }^{3}$ Pediatrics, Chonnam National University Medical School, Gwangju, Korea

Purpose $\underline{e}$ : To ascertain the factors associated with the proportion of death certificate only (DCO) cases contained in the Kwangju Cancer Regis try (KCR) that are not as yet in the good range.

Materials and Methods: The dis tribution of DCO cas es was analyzed by sex, age, cancer site, his tological verification (HV) as well as the physician's death certificate $s$ tatus.

Res ults: All cases $(n=4,243)$ in Kwangju diagnosed as having cancer between 1997 and 1998 were registered with the KCR. Death certificates $(n=2,390)$ reporting cancer as the causes of death were collected from the National Statis tics Office and reviewed with hos pital data linkage and a total of 590 cases were regis tered as DCO. DCOs accounted for $\mathbf{1 2 . 2 \%}$ (male $\mathbf{1 2 . 8 \%}$, female $11.5 \%$ ) of all regis trations in Kwangju, $1997 \sim 1998$. The proportion of DCO cases was high in s ubjects under 15 (male

\section{서 론}

지역 암등록은 한정된 지역 내에서 암의 발생 수준을 신 빙성 있게 파악하고 그 발생 수준을 타 지역의 발생 수준 과 비교하여 암 관련요인에 대한 연구의 기초자료로 활용 하는데 있다(1). 대부분의 지역 암등록은 지역의 단위인구 당 암 발생률을 산출하는데 있어 미등록 암 발생을 줄이 기 위하여 병원 암등록 자료에 사망신고자료를 추가하고 있다. 그러나 사망신고자료는 그 동안 많은 사람들에 의 해 신뢰성에 대한 문제가 거론되어 왔으며(2 4), 사망신 고서를 기반으로 한 통계가 너무 부정확하여 연구나 보건 기획에 부적당하다고 주장하기도 한다(5). 그럼에도 불구 하고 사망신고서는 지역 암등록의 효과적 운영에 중요한

Correspondence: Su Jin Lee, Department of Preventive Medicine, Chonnam National University Medical School, 5 Hak 1(il)-dong, Dong-gu, Gwangju 501-746, Korea. (Tel) 062-220-4170, (Fax) 062-233-0305, (E-mail)sujin95 @netian.com

Received July 30, 2001, Accepted November 22, 2001 13.5\%,female 9.4\%) as well as those 75 and over (male $\mathbf{2 0 . 3 \%}$, female $27.2 \%$ ). For cancers ites, the proportion of DCO cas es was high (over $10 \%$ ) for live r, bro nchus -lung, es ophagus and pancreas and low (under 3\%) for skin, bladder, uteri cervix and breast. The proportion of DCO cases was inversely associated with $\mathrm{HV} \%$. Whe n the death certificate was is sued by phys ic ian, the poss ibility of DCO dec reased.

Conclusion: The proportion of DCO is positively associated with increas ing age and negatively associated with $\mathrm{HV} \%$ and the issuance of a physician's death certificate. These findings suggest that further sociocultural efforts are required to reduce the DCO proportion. (Cancer Research and Treatment 2001;33:512-519)

Key Words : Cancer regis try, Death certificate, Kwangju, Ko rea

여러 가지 기능을 한다(5). 즉, 암 발생에 대한 정보의 보 완적인 자료원으로 활용되고, 충실성과 타당성의 정도관 리를 위해 사용되며, 등록된 환자의 결과(생존)에 대한 연 구에서도 이용된다(2,4 6).

사망신고자료에만 존재하는 암 환자(death certificate only, $\mathrm{DCO}$ )는 발생 암 환자 중에서 암에 대한 정보가 사망신고 서에만 유일하게 제시되어 있으며 역추적이 불가능하였 던 경우(1,6 9)이며, 사망신고를 통해 최초로 암을 인지 (death certificate notification, DCN)하여 의무기록과 기타의 방법으로 암 진단이 확인되지 못한 사람들을 발생 암 환 자로 지역 암등록에 포함시키는 경우이다. 따라서 사망신 고자료의 질이 낮은 경우는 암 발생률이 상당히 과대 추 정될 가능성이 클 것이다(5). $\mathrm{DCO}$ 는 지역 암등록의 상황 에 따라 암 발생자로 포함시키거나 혹은 제외하기도 한다.

광주지역에서는 1997년 광주암등록사업단(Kwangju Cancer Registry, KCR)이 구성되어 지속적으로 지역 암등록사업 을 수행하고 있으며, 통계청의 사망자료를 활용하여 지역 암등록의 완성도를 높이고 있다. 즉, 사망신고서에 사망원 인이 암으로 신고된 기록들을 발췌하여 $\mathrm{KCR}$ 의 기존 자료 
은행과 대조를 통해 이미 등록 되어있는 경우는 사망일과 사망원인을 추가 입력하고, 기등록 되어있지 않은 경우에 는 광주지역 병원의 의료이용을 역추적하여 진단의 사실성 을 확인하고 있다. 이러한 과정을 거친 후에도 남는 사망신 고자료는 $\mathrm{DCO}$ 로 간주하여 등록에 추가하고 있다(10 12).

일반적으로 $\mathrm{DCO}$ 로 등록될 가능성이 높은 경우는 사망 원인이 암이 아닌 경우 외에 암이라 할지라도 사후 진단 이 이뤄졌거나, 가정에서 사망하였을 때, 혹은 적극적인 치료를 받지 않았을 때이다. 또한 생존기간이 짧은 암이 거나 지역 암등록에서 포착할 수 있는 의료기관에서 치료 를 받지 않은 경우도 $\mathrm{DCO}$ 에 포함될 것으로 추정해 볼 수 있다 $(9,13)$. 이런 $\mathrm{DCO}$ 는 암등록의 질과 신뢰성에 영향을 끼칠 수 있다. 만약 $\mathrm{DCO}$ 가 지역 암등록에서 높은 분율을 차지하게 된다면 발생부위와 진단시기 그리고 사망원인 등이 부정확하여 암의 발생, 생존 및 치료율 산출에 편향 을 야기할 수 있다. 또한 확실한 진단시기를 파악하기 어 렵기 때문에 생존분석에서도 제외되게 된다 $(8,13,14)$. 국내 에서는 몇 개의 보고서에서만 $\mathrm{DCO}$ 분율에 대해 간략히 제시하고 있는 정도이며 $(10,11,15)$, 외국의 경우도 최근에 서야 DCO 분율과 관련요인에 대하여 연구를 하고 있는 상황이다 $(5,13,16,17)$. 이에 따라 광주지역(1997 1998)의 $\mathrm{DCO}$ 의 구조적 특성을 파악하고, 이와 관련된 인자를 확 인하여 그 분율을 줄여나갈 수 있는 방안을 모색하는데 기초 자료로 활용하고자 본 연구를 시행하였다.

\section{대상 및 방법}

\section{1) 대상}

본 연구는 광주광역시에 거주하는 $1,326,478$ 명 $(18,19)$ 중 1997년 1월 1일부터 1998년 12월 31일까지 2년 동안의 암 발생자를 대상으로 하였다. 2 년간 총 암 발생은 4,243 건 (남자 2,360 건, 여자 1,883 건)으로 이 중에는 광주지역의 의료기관에서 확인되지 않고 타 지역의 의료기관에서 확 인되어 중앙암등록사업단(Central Cancer Registry; CCR)을 통해 등록한 411건이 포함되어있다.

사망자료는 1997년 1월 1일부터 1998년 12월 31일까지 통계청 사망자료에서 사망 당시 주소가 광주로 되어있는 11,279 건(20,21) 중, 사망원인이 암(ICD-10; C00-C97)으로 언 급된 2,390 건(남자 1,554 건, 여자 836 건)을 대상으로 하였다.

\section{2) $\mathrm{KCR}$ 의 $\mathrm{DCO}$ 산출 방법}

1997 1998년 광주지역의 사망신고 중 암으로 신고된 건수는 총 2,390 건으로, 주민등록번호를 검색하여 $\mathrm{KCR}$ 의 등록 여부를 확인하였다. 이 중 이미 KCR 자료은행에 등 록된 경우는 1,583 건(66.2\%)이었고, 이들에 대해서는 사망 원인과 사망일을 첨부하는 작업을 하였다. 또한 미 등록 된 암 사망자 807건(33.8\%)에 대해서는 광주지역에서 전 산화가 잘 되어있는 2 개 수련병원의 의료이용을 역추적하

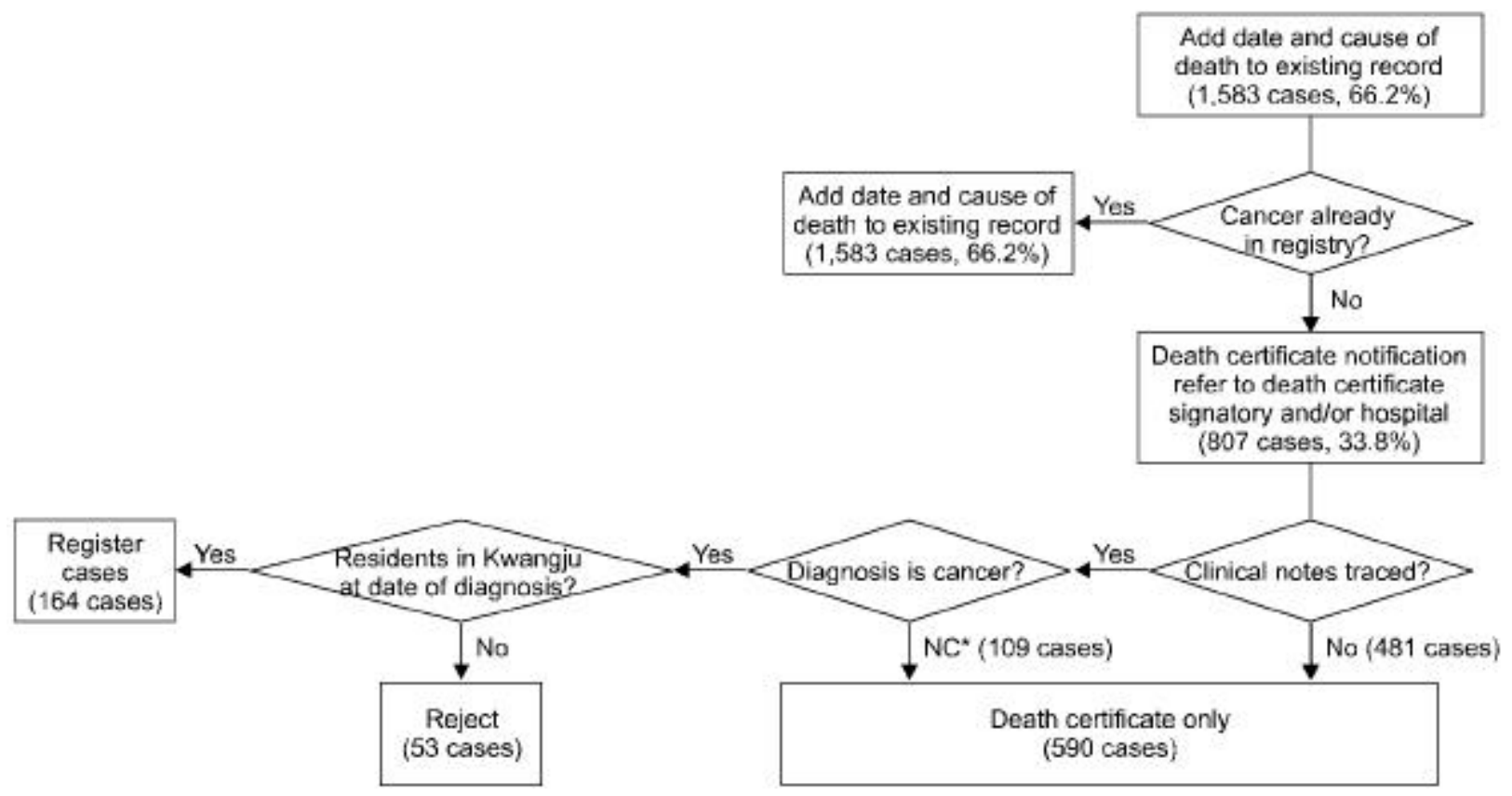

Fig. 1. Detection procedure for the death certificate only (DCO) in Kwangiu Cancer Registry (KCR). *'NC' denotes for 'Not Confirmed' , which dose not mean the case is not cancer, but means the case could not be confirmed as cancer. 
514 Cancer Research and Treatment 2001;33(6)

였다. 의무기록 열람을 통해 암에 대한 병력을 확인할 수 있었던 164 건은 $\mathrm{KCR}$ 의 자료은행에 추가로 등록하였고, 암 발생 당시 타 지역 거주자로 확인된 경우는 53 건으로 $\mathrm{KCR}$ 에 등록시키지 않았다. 이러한 노력에도 불구하고 암 에 대한 어떠한 증거도 확인할 수 없었던 590건은 $\mathrm{DCO}$ 로 처리하였다.

이러한 과정은(Fig. 1)에 간략히 제시하였다.

3) 분석방법

$\mathrm{DCO}$ 의 자료원인 사망신고서는 사망원인이 ICD- 10 으로
기입되어 있어, $\mathrm{KCR}$ 자료와 비교를 용이하게 하기 위해 International Classification of Diseases for Oncology Second Edition(22)을 바탕으로 ICD-O로 변환하였다.

$\mathrm{DCO} \%$ 는 광주광역시 지역 암등록과 사망자료를 이용하 여 전체 또는 특정 요인별로 분석하였다.

$\mathrm{DCO} \%$ 는 다음과 같은 식으로 구하였다

$$
D C O \%=\frac{\text { Number } g \text { true DCOs during two years }}{\text { Total number } g \text { cancer cases during two years }}=100
$$

Table 1. General characteristics of death certificate only (DCO)

\begin{tabular}{|c|c|c|c|}
\hline \multicolumn{2}{|c|}{ Variables } & \multirow{2}{*}{$\begin{array}{l}\text { No. } \\
345\end{array}$} & \multirow{2}{*}{$\begin{array}{r}\% \\
58.5\end{array}$} \\
\hline Sex & Male & & \\
\hline & Female & 245 & 41.5 \\
\hline \multirow[t]{2}{*}{ Year at death } & 1997 & 296 & 50.2 \\
\hline & 1998 & 294 & 49.8 \\
\hline \multirow[t]{6}{*}{ Age group (years) } & Under 15 & 8 & 1.4 \\
\hline & $15 \sim 29$ & 10 & 1.7 \\
\hline & $30 \sim 44$ & 54 & 9.2 \\
\hline & $45 \sim 59$ & 113 & 19.2 \\
\hline & $60 \sim 74$ & 240 & 40.7 \\
\hline & 75 and over & 165 & 28.0 \\
\hline \multirow[t]{3}{*}{ Place of death } & Home & 379 & 64.2 \\
\hline & Hospital & 170 & 28.8 \\
\hline & Others & 41 & 6.9 \\
\hline \multirow{3}{*}{$\begin{array}{l}\text { Issuer of } \\
\text { death certificate }\end{array}$} & Physician & 339 & 57.5 \\
\hline & Herb doctor & 3 & 0.5 \\
\hline & No & 248 & 42.0 \\
\hline \multirow[t]{6}{*}{ Occupation } & Unemployed & 137 & 23.2 \\
\hline & Farmer \& fisher & 65 & 11.0 \\
\hline & Engineer & 26 & 4.4 \\
\hline & Service worker & 26 & 4.4 \\
\hline & Others & 66 & 11.2 \\
\hline & No & 270 & 45.8 \\
\hline \multirow[t]{5}{*}{ Education } & Elementary school & 211 & 35.8 \\
\hline & Middle school & 74 & 12.5 \\
\hline & High school & 87 & 14.7 \\
\hline & College \& university & 50 & 8.5 \\
\hline & No and uneducated & 168 & 28.5 \\
\hline \multirow[t]{10}{*}{ Cancer site } & Liver & 143 & 24.2 \\
\hline & Stomach & 115 & 19.5 \\
\hline & Lung & 109 & 18.5 \\
\hline & Colo-rectum & 27 & 4.6 \\
\hline & Pancreas & 24 & 4.1 \\
\hline & Haematopoietic system & 23 & 3.9 \\
\hline & Unknown primary site & 18 & 3.1 \\
\hline & Esophagus & 15 & 2.5 \\
\hline & Gall bladder, etc. & 14 & 2.4 \\
\hline & Uterus, nos & 14 & 2.4 \\
\hline
\end{tabular}


$\mathrm{Su}$ Jin Lee, et al: Proportion of DCO Cases and Its Related Factors, KCR $\mathbf{5 1 5}$

$\mathrm{DCO} \%$ 는 성별, 연령 그리고 주요 암 부위에 따라 구하 였다. 또한 조직학적 확진율(histological verification; HV\%) 이 낮을 경우 $\mathrm{DCO}$ 가 높을 것이란 가설 하에 전체 암 부 위에서 각각 성별 및 연령에 따라, 그리고 암 부위에서 $\mathrm{HV} \%$ 와 $\mathrm{DCO} \%$ 사이의 관계를 비교하였다. 또한 사망시 의 사의 사망진단서가 첨부된 경우 $\mathrm{DCO}$ 로 분류될 가능성이 적을 것이란 가설을 검토하기 위하여 사망자료 중에서 의사 진단서 첨부 유무에 따른 $\mathrm{DCO} \%$ 를 비교하였다. 연령은 15 세 간격으로 15 세 미만, $15 \sim 29$ 세, $30 \sim 44$ 세, $45 \sim 59$ 세, $60 \sim$ 74세, 75 세 이상의 6 개의 연령군으로 분류하여 분석하였다.

\section{결 과}

\section{1) $\mathrm{DCO}$ 의 일반적인 특성}

총 590 건의 $\mathrm{DCO}$ 는 남자가 $58.5 \%$ 인 345 건, 여자가

Table 2. Proportion of death certificate only (DCO) by sex

\begin{tabular}{lcccc}
\hline Sex & $\begin{array}{c}\text { KCR* } \\
(\mathrm{A})\end{array}$ & $\begin{array}{c}\text { Death } \\
\text { Certificate }\end{array}$ & $\begin{array}{c}\text { DCO } \\
(\mathrm{B})\end{array}$ & $\begin{array}{c}\text { DCO\% } \\
(\mathrm{B} /(\mathrm{A}+\mathrm{B}))\end{array}$ \\
\hline Male & 2,360 & 1,554 & 345 & 12.8 \\
Female & 1,883 & 836 & 245 & 11.5 \\
All & 4,243 & 2,390 & 590 & 12.2 \\
\hline
\end{tabular}

*Kwangju Cancer Registry
$41.5 \%$ 인 245 건으로 남자가 좀 더 높은 분율을 차지하였 다. 연령은 $60 \sim 74$ 세가 $40.7 \%, 75$ 세 이상이 $28.0 \%$ 으로 전 체의 $69.5 \%$ 를 나타냈다. 사망장소는 가정이 $64.2 \%$, 병원 이 $28.8 \%$ 로 가정에서 사망한 경우가 많았으며, 의사의 사 망진단서가 첨부된 경우는 $57.5 \%$ 에 불과하였다. 주된 암 부위로는 간, 위, 폐 등으로 이들이 전체의 $62.2 \%$ 를 차지 하였다(Table 1).

2) 성별, 연령, 암 부위에 따른 $\mathrm{DCO} \%$

(1) 성별: 1997 1998년, $\mathrm{DCO}$ 는 모든 등록의 $12.2 \%$ 를 차

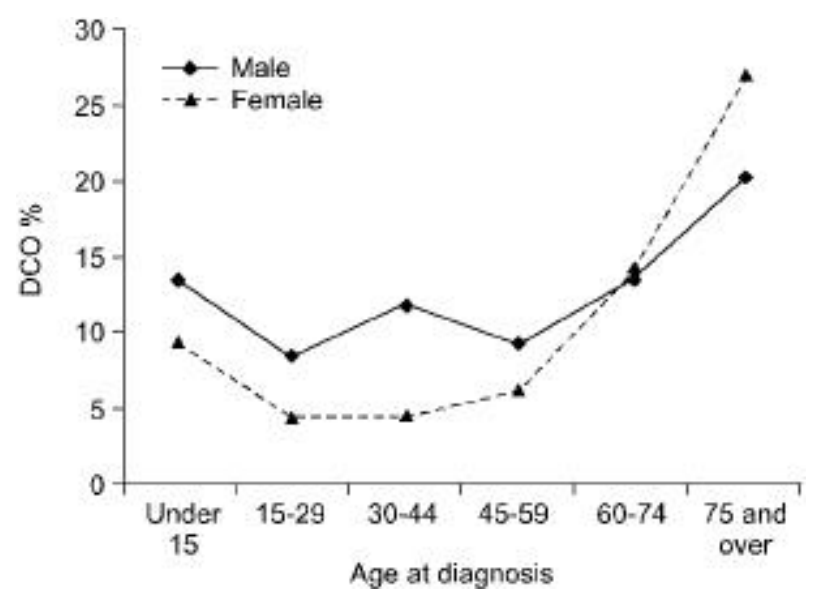

Fig. 2. Proportion of death certificate only (DCO) by sex and age at diagnosis.

Table 3. Proportion of death certificate only (DCO) by selected cancer sites

\begin{tabular}{|c|c|c|c|c|}
\hline & \multicolumn{2}{|c|}{ Male } & \multicolumn{2}{|c|}{ Female } \\
\hline & Cancer site & $\mathrm{DCO} \%$ & Cancer site & DCO $\%$ \\
\hline \multirow[t]{5}{*}{ Over $14 \%$} & Liver & 20.0 & Liver & 27.4 \\
\hline & Bronchus, lung & 18.2 & Pancreas & 26.2 \\
\hline & Haematopoietic system & 18.2 & Esophagus & 25.0 \\
\hline & Esophagus & 14.9 & Bronchus, lung & 17.3 \\
\hline & & & Stomach & 14.5 \\
\hline \multirow[t]{6}{*}{$5 \sim 14 \%$} & Pancreas & 11.4 & Haematopoietic system & 13.0 \\
\hline & Stomach & 10.6 & Gall bladder, etc. & 9.9 \\
\hline & Larynx & 7.8 & Ovary & 8.3 \\
\hline & Gall bladder, etc. & 7.3 & Bladder & 7.4 \\
\hline & Prostate & 7.0 & Colo-rectum & 7.3 \\
\hline & Colo-rectum & 5.1 & & \\
\hline \multirow[t]{4}{*}{ Under $5 \%$} & Skin & 2.9 & Breast & 4.9 \\
\hline & Bladder & 2.5 & Skin & 3.8 \\
\hline & & & Uterine cervix & 2.1 \\
\hline & & & Thyroid & 0.5 \\
\hline
\end{tabular}


지하였고, 남자가 $12.8 \%$, 여자는 $11.5 \%$ 로 남자가 좀 더 높 게 나타났다(Table 2).

(2) 연령: $\mathrm{DCO} \%$ 의 연령별 분포는 남, 녀 모두 연령의 양극단인 15 세 미만과 75 세 이상에서 높게 나타났다. 성 별로는 대부분의 연령군에서 남자의 $\mathrm{DCO} \%$ 가 여자보다 더 높았으나 75세 이상의 고령군에서는 여자의 $\mathrm{DCO} \%$ 가 더 높아지는 성별 역전 현상을 보였다(Fig. 2).

(3) 암 부위: $\mathrm{DCO} \%$ 는 남, 녀 모두 간, 기관지-폐, 식도, 췌장, 조혈조직계, 위 등의 부위에서 높았으며( $10 \%$ 이상), 남자의 경우 피부와 방광, 여자의 경우 자궁경부와 갑상 선 등의 부위에서 낮은 분율(3\% 미만)을 보였다(Table 3$)$.

\section{3) $\mathrm{HV} \%$ 와 $\mathrm{DCO} \%$ 의 관계}

(1) 연령: 남자의 $15 \sim 29$ 세, 여자의 $30 \sim 44$ 세에 $\mathrm{DCO} \%$ 가

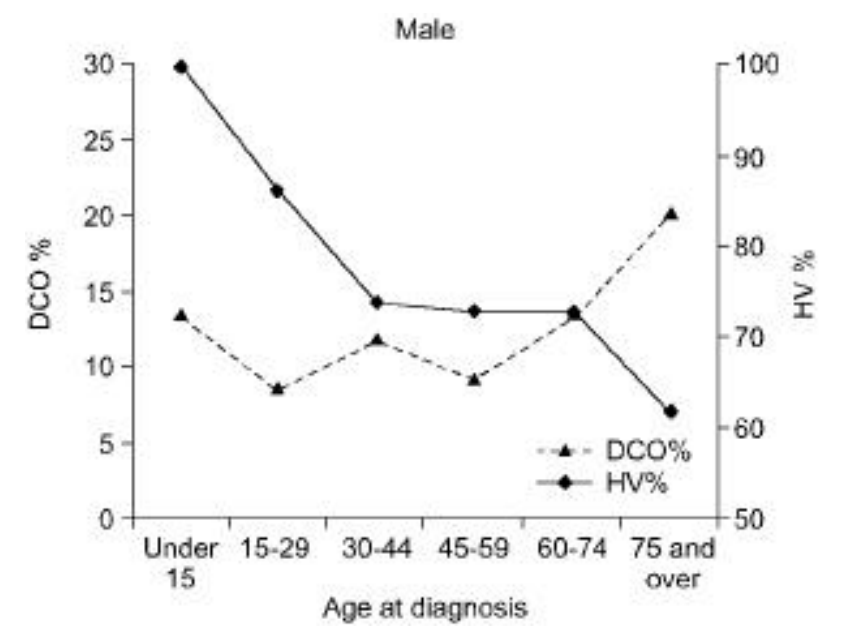

$8.5 \%, 4.4 \%$ 로 가장 낮았고 $\mathrm{HV} \%$ 는 $86.2 \%, 92.8 \%$ 로 나타났 다. 또한 남, 녀 모두 75 세 이상에서 $\mathrm{DCO} \%$ 가 $20.3 \%$, $27.2 \%$ 로 가장 높았으며, $\mathrm{HV} \%$ 는 $61.9 \%, 52.9 \%$ 로 가장 낮 았다. 특히 여자에서는 $\mathrm{HV} \%$ 가 감소함에 따라 $\mathrm{DCO} \%$ 가 증가하는 경향을 보이고 있다(Fig. 3).

(2) 암 부위: 남, 녀 모두 간, 기관지-폐, 뇌, 췌장 등의 부위에서 $\mathrm{DCO} \%$ 가 $10 \%$ 이상으로 높았으며, $\mathrm{HV} \%$ 는 $75 \%$ 미만으로 낮았다. 또한 남자의 방광, 여자의 유방, 자궁경 부 등의 부위에서 $\mathrm{DCO} \%$ 가 $5 \%$ 미만으로 낮은 경우 $\mathrm{HV} \%$ 는 $85 \%$ 이상으로 나타났다(Table 4).

\section{4) 의사의 사망진단서 첨부 유무에 따른 $\mathrm{DCO} \%$}

사망자를 대상으로 살펴본 경우, 남, 녀 모두에서 의사 진단서가 첨부되었을 때 $(21.0 \%)$ 가 첨부되지 않았을 때

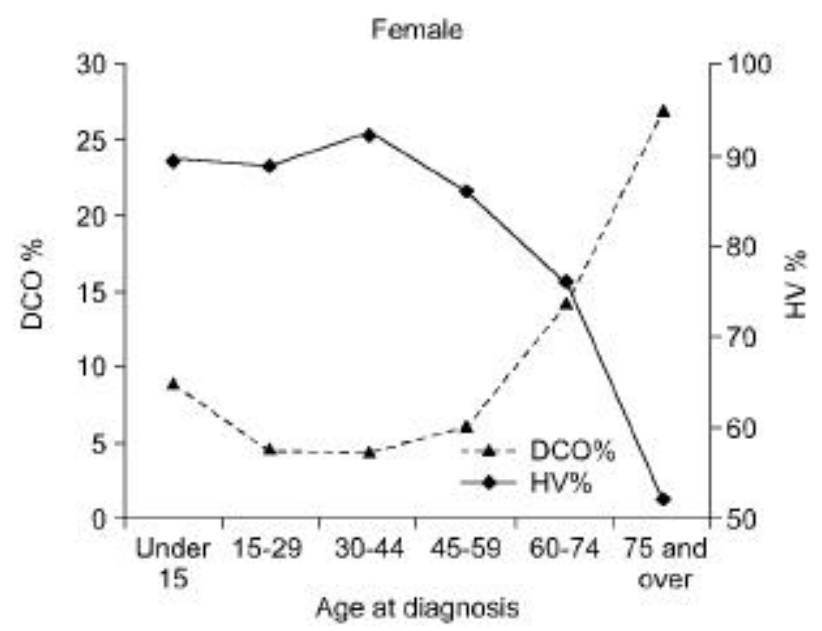

Fig. 3. Proportion of histological verification (HV) and death certificate only (DCO) by age group at diagnosis in male and female.

Table 4. Proportion of histological verification (HV) and death certificate only (DCO) by selected cancer sites in male and female

\begin{tabular}{|c|c|c|c|c|c|}
\hline \multicolumn{3}{|c|}{ Male } & \multicolumn{3}{|c|}{ Female } \\
\hline Cancer site & $\mathrm{DCO} \%$ & $\mathrm{HV} \%$ & Cancer site & $\mathrm{DCO} \%$ & $\mathrm{HV} \%$ \\
\hline Liver & 20.0 & 21.5 & Liver & 27.4 & 14.9 \\
\hline Bronchus, lung & 18.2 & 74.8 & Pancreas & 26.2 & 26.7 \\
\hline Brain & 15.2 & 71.8 & Esophagus & 25.0 & 83.3 \\
\hline Esophagus & 14.9 & 83.8 & Brain & 20.2 & 71.4 \\
\hline Kidney & 14.7 & 82.8 & Bronchus, lung & 17.3 & 59.7 \\
\hline Pancreas & 11.4 & 43.5 & Stomach & 14.5 & 85.6 \\
\hline Stomach & 10.6 & 92.7 & Bladder & 7.4 & 76.0 \\
\hline Prostate & 7.0 & 84.9 & Colo-rectum & 7.3 & 87.4 \\
\hline Colo-rectum & 5.1 & 88.4 & Kidney & 6.7 & 71.4 \\
\hline \multirow[t]{2}{*}{ Bladder } & 2.5 & 85.9 & Breast & 4.9 & 96.6 \\
\hline & & & Uterine cervix & 2.1 & 96.8 \\
\hline
\end{tabular}



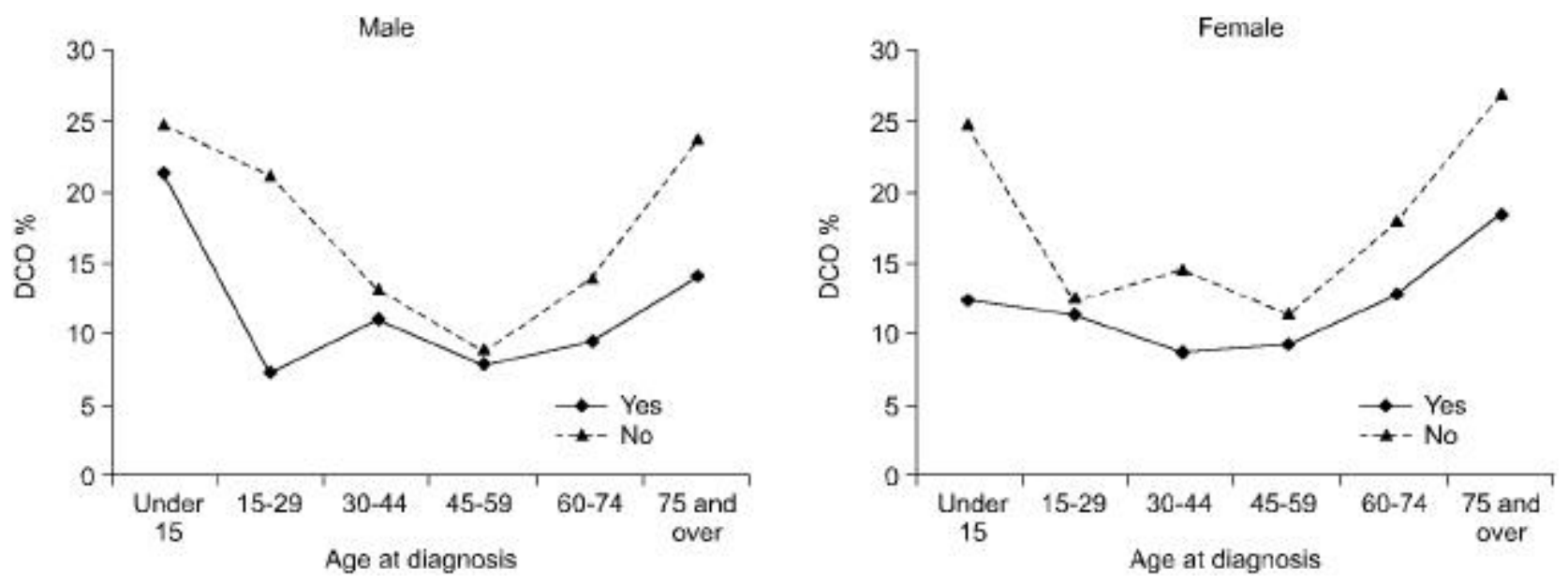

Fig. 4. Relation between age at diagnosis and proportion of death certificate only (DCO) by attachment of physician's death certificate in only deceased cases, in male and female.

(32.7\%)보다 더 낮은 분율을 나타냈고, 남, 녀에서도 유사 한 결과를 보였다. 또한 전 연령층에서 의사진단서가 첨 부되지 않은 경우 $\mathrm{DCO} \%$ 가 더 높은 것으로 나타났다. 남 자에서 $15 \sim 29$ 세의 진단서가 첨부되지 않은 경우 $\mathrm{DCO} \%$ 가 $42.9 \%$ 였고, 첨부된 경우 $15.0 \%$ 로 나타났고, 75 세 이상 에서는 각각 $47.9 \%, 28.6 \%$ 등으로 나타났다. 여자에서는 30 44세에서 진단서가 첨부되지 않은 경우 $29.4 \%$, 첨부 된 경우 $17.8 \%$ 였으며, 75 세 이상에서는 각각 $54.7 \%, 37.9 \%$ 등을 보였다(Fig. 4).

\section{고 찰}

지역 암등록은 암 발생과 생존에 대한 정보를 제공하는 공중보건 연구의 귀중한 자료원으로, 등록의 높은 완성도 를 보이기 위해서는 실제 발생한 암환자를 최대한 포착하 여 누락을 가능한 줄임으로써 일정 수준 이상의 충실성를 확보하는 동시에 등록된 자료의 내용이 정확하고 진실에 가깝도록 타당성이 보장되어야 한다 $(5,6,8)$. 일반적으로 사 용하는 지역 암등록의 충실성의 평가방법으로는 $\mathrm{DCO} \%$ 와 사망률/발생률 비(mortality/incidence ratio, M/I ratio) 등의 지표를 산출하는 방법, 이미 등록된 환자의 의무기록을 재확인하는 방법, capture-recapture 방법 등이 있다. 그리고 등록 내용의 타당성(validity)을 평가하는 방법으로는 $\mathrm{DCO} \%$, $\mathrm{HV} \%$, 등록 환자중 원발부위가 불분명한 환자의 분율 (primary site unknown, $\mathrm{PSU} \%$ ), 등록 환자중 연령이 미상인 환자의 분율(age unknown, Age UNK\%) 등이 있다. 이와 같이 $\mathrm{DCO}$ 는 암등록사업을 평가하는데 자주 이용되고 있다. $\mathrm{DCO} \%$ 는 사망자료의 유용성, 사망원인의 질, 역추적 할 수 있는 기관 등 지역적 상황을 고려하여 해석해야 한다
$(5,6,9)$. 높은 $\mathrm{DCO} \%$ 는 암등록의 타당성과 신뢰성에 영향 을 미치지만, 낮은 $\mathrm{DCO} \%$ 가 충실성을 완전히 보증할 수 있는 것은 아니다. 비록 효율적인 환자 발견을 제시할 수 있기는 하지만, 그것은 $\mathrm{DCN}$ 의 효율적인 역추적의 결과와 동일하기 때문이다. 또한 사망자료는 진단적 정보가 결핍 되어있기 때문에, 정확성과 정밀성을 말하기가 어렵다. 따 라서 $\mathrm{DCO} \%$ 가 지역 암등록에서 높은 분율을 차지하게 되 면 자료의 타당성이 떨어진다는 것을 의미한다(5 7).

현재 어느 정도까지 $\mathrm{DCO} \%$ 를 받아들일 수 있겠는가하 는 수용성에 대해서는 특별한 객관적인 기준이 제시되어 있지는 않지만, IARC (International Agency for Research on Cancer)에서는 5 개 대륙에서의 암발생에 게재할 암등록 자료를 심사하는 기준으로 $\mathrm{DCO}$ 가 전체 암 발생 중 $10 \%$ 이하인 경우는 $\mathrm{A}$ 군(A=good), $11 \sim 19 \%$ 는 $\mathrm{B}$ 군(B=acceptable), $20 \%$ 이상일 때는 $\mathrm{C}$ 군 $(\mathrm{C}=$ not acceptable)으로 분류(23)하고 있다. $\mathrm{KCR}$ 의 경우는 $12.2 \%$ 로 $\mathrm{B}$ 군, 즉 acceptable로 분류되 어 아직 세계적으로 인정되는 $10 \%$ 이하에는 속하지 못하 고 있다.

이러한 IARC의 기준 외에도 Parkin(6)은 어떤 지역 암등 록에서도 $\mathrm{DCO} \%$ 가 $24 \%$ 이상을 초과해서는 안된다고 주 장하고, Jensen과 Storm은 미국의 지역 암등록에서 $1 \%$ 이 하이거나 $15 \%$ 이상을 나타낼 경우에는 모두 유용하지 못 하다고 발표하였으나, 미국에서 표본지역을 대상으로 전 국적인 규모로 시행되는 SEER (Surveillance, Epidemiology, and End Results) 프로그램에서는 사망자의 역추적 이후, 등록된 모든 암 부위에서 $1.5 \%$ 를 초과하면 안된다고 설정 하고 있다(24). 캐나다에서는 2 3\%가 유용하며, $5 \%$ 이하 일 경우는 어느 정도 수용할 수 있다(25)고 하며 북미, 서 유럽, 오스트레일리아, 뉴질랜드에서는 모든 암 부위에서 
$12 \%$ 를 초과해서는 안된다(5)고 설정하고 있기도 하다. 광주의 경우 $\mathrm{DCO} \%$ 가 모든 등록의 $12.2 \%$ 로서 서울 $16.2 \%$ (1992 1995), 부산 $18.9 \%$ (1995 1997), 인천 $15.7 \%$ (1997) 등 타 지역에 비해 낮지만 국제적으로 인정받을 수 있는 수준에는 아직 도달하지 못하고 있으며, SEER (198 $8 \sim 1992,0.93 \%)$, 잉글랜드와 웨일즈(1987 1989, 1.6\% $13.8 \%)$, 캐나다 $1984 \sim 1988,2.0 \%)$ 등 오랜 역사를 가지고 있는 지역에 비하면 상대적으로 그 분율이 높다고 할 수 있다 $(10,11,16,24)$.

본 연구에서 나타난 결과를 살펴보면 1997 1998년, 광 주지역의 $\mathrm{DCO}$ 는 590 건으로 전체 암 발생의 $12.2 \%$ 를 차지 했으며, 남자는 $12.8 \%$, 여자는 $11.5 \%$ 로 성별에 따른 차이 는 적었다. 그러나 남, 녀 모두 연령의 양극단인 15 세 미 만과 75세 이상에서 $\mathrm{DCO} \%$ 가 높게 나타났다. 15 세 미만에 서는 예상외로 $\mathrm{DCO} \%$ 가 높았으나, 이것은 전체 암 발생이 69건으로 적고, 연구기간이 2년으로 짧아 아직 안정적인 자료가 아니기 때문에 추후 관찰이 더 필요할 것으로 보 인다. 75 세 이상의 고연령층에서 $\mathrm{DCO}$ 가 높은 분율을 차 지하였는데, 이는 다른 연령층에 비하여 환자가 치료자체 에 소극적이거나, 의사가 치료요법을 시행하려고 계획하 지 않을 뿐만 아니라 검사 자체가 노인에게 위험할 수 있 어 시행하기를 꺼리기 때문으로 추정된다. 이러한 현상은 고연령의 경우 조직학적으로 확진을 받는 분율을 낮추는 현상(5)에도 영향을 미치게 되는데, 이는 본 연구의 결과 와도 동일하게 나타났다. 또한 $\mathrm{KCR}$ 에서는 악성 종양이라 는 확실한 진단이 이루어지지 않은, 즉 진단배제 대상이 나 양성 종양은 암 발생자로 등록하지 않고 있으나, 사망 신고에는 선행사인에 암으로 명시되는 경우도 있으리라 생각된다.

성별로는 대부분의 연령군에서 남자의 $\mathrm{DCO} \%$ 가 여자보 다 더 높았으나, 75 세 이상의 고령군에서는 여자의 $\mathrm{DCO} \%$ 가 더 높아지는 성별 역전 현상을 보였다. Pollock 와 Vickers(13)에 따르면 연령을 40세 미만, 40 64세, 65 74 세, 75 세 이상의 4 개의 연령군으로 나누어 분석하였는데, 본 연구에서 나타난 결과와 마찬가지로 남, 녀 모두 연령 이 증가하면서 $\mathrm{DCO}$ \%가 높아졌으며 75세 이상에서만 여 자(34.8\%)의 $\mathrm{DCO} \%$ 가 남자(32.4\%)에 비해 상승된 것을 확 인할 수 있었다.

$\mathrm{DCO} \%$ 는 암 부위에 따라서도 차이를 보였는데, 남, 녀 모두 간, 기관지-폐, 식도, 췌장 등의 부위에서 $10 \%$ 이상 의 분율을 보였으며, 남자의 경우 피부와 방광, 여자의 경 우 자궁경부와 갑상선 등의 부위에서는 $3 \%$ 미만으로 나 타났다. 외국의 경우, 미국의 코네티컷(1991 1995)에서는 간, 췌장, 다발성 골수종이 $5 \%$ 이상, 기관지-폐, 백혈병,
난소 등이 $3 \sim 5 \%$, 방광, 갑상선 등이 $1 \%$ 미만으로 각각 나타났다. 캐나다(1991 1995)에서는 췌장, 간 등에서 6\% 이상, 위, 기관지-폐, 백혈병, 다발성 골수종 등이 $2 \sim 4 \%$, 피부, 전립선, 고환, 방광, 갑상선 등에서 $1 \%$ 미만을 보였 다(16). 또한 잉글랜드 남동부 지역(1987 1989)은 폐, 위, 췌장 등이 모든 등록의 $33 \%$ 정도를 차지했고, 전립선, 대 장, 직장, 뇌 등은 $17 \sim 19 \%$, 피부, 고환 등에서는 $10 \%$ 미 만을 나타냈다(13). 국내의 경우는 현재까지 암 부위에 따 른 $\mathrm{DCO}$ 분율을 구체적으로 제시한 자료가 거의 없는 실 정이나, 최근 부산지역에서 1998년도 암 발생자를 대상으 로 암 부위별로 각각의 $\mathrm{DCO} \%$ 를 제시하였다. 남, 녀 모두 간, 췌장, 기관지-폐 등의 부위에서 $20 \%$ 이상으로 나타났 고, 식도, 위, 대장 등에서는 $15 \sim 20 \%$ 정도의 분율을 보였 다. 그리고 남자의 경우 피부, 여자의 경우 갑상선, 자궁체 부 등에서 $3 \%$ 미만으로 확인되었다(15). 암 부위에 따른 $\mathrm{DCO} \%$ 는 각각의 지역 암등록의 상황에 따라 차이가 있지 만, 일반적으로 예후가 좋지 않은 췌장, 간, 기관지-폐, 위 등에서 높은 분율을 차지했으며, 예후가 좋은 피부, 고환, 갑상선 등의 부위에서 낮은 분율을 보였다. 이는 예후가 좋은 암인 경우 사망진단서에 사망원인을 더 부정확하게 기재했을 가능성이 높다고 생각되나, KCR이 아직 등록의 초창기에 있기 때문에 향후 이에 대한 분석이 수행되어져 야 할 것이다. 또한 조직학적으로 확진을 받는 분율이 높 은 부위일수록 $\mathrm{DCO} \%$ 가 낮은 것을 확인할 수 있었다. $\mathrm{HV} \%$ 는 생검의 접근성 및 대안적인 진단 방법의 가용성 에 따라 달라지는데, 뇌와 췌장과 같이 접근하기 곤란한 부위나, 컴퓨터 단층촬영, 자기공명영상, 혈관촬영, 초음파 등의 검사로 진단할 수 있는 간, 기관지-폐 등의 암은 $\mathrm{DCO} \%$ 가 높게 나타났다 $(5,10,11)$.

사망자를 대상으로, 의사의 사망진단서 첨부 유무에 따 른 $\mathrm{DCO} \%$ 를 살펴본 결과 전 연령층에서 의사진단서가 첨 부되지 않았을 때 $\mathrm{DCO} \%$ 가 더 높은 것을 볼 수 있었다. 의사의 사망진단서 첨부는 사망신고자료의 정확도를 더 높이는 것으로 생존해 있는 동안 한 번 이상 의료기관을 이용했을 것이라고 생각할 수 있다. 그러나 의사진단서가 첨부되지 않은 경우는 사망신고서의 사망원인이 더 부정 확했을 것이고 실제 암으로 의료기관을 이용하지 않았을 수도 있어, 암 발생을 과대 추정할 가능성이 있다. 1997년 광주의 경우 의사의 사망진단서 첨부율은 $67.0 \%$ 로 전국 평균 74.7\%에도 미치지 못하고 있다. 이는 1991년 $16.9 \%$, 1995년 $32.1 \%$ 등 과거에 비해 비교적 의사진단율이 높아 지기는 했지만 여전히 사망자료만을 자료원으로 하는 $\mathrm{DCO}$ 의 신빙성에 문제가 제기 될 수 있다. 따라서 사망자 료의 질을 향상시키기 위해서는 의사진단서 첨부율을 높 
이고, 인우증명으로 사망신고서를 대신할 수 있는 현 사 망신고제도에 대해 개선이 필요하다. 아울러 의료인의 적 극적인 노력이 중요하겠다.

본 연구에서는 다음과 같은 제한점이 있었다.

첫째, 방법론에 있어 타 지역과의 비교 연구를 시행하 지 않았다는 것이다. 이는 광주지역 내에서 $\mathrm{DCO}$ 분율과 그것의 관련요인을 파악하고자 하였기 때문이기도 하지 만, 실제 비교를 위한 이상적인 지역이 현실상 존재하지 않고, 타 지역 암등록에서 동일한 특성의 자료를 구하는 데 어려움이 있어 내적 비교를 수행하게 되었다.

둘째, 현재 $\mathrm{KCR}$ 의 안정성에 대한 전제를 할 수 없다는 것이다. 안정성이란 같은 암등록에서 5 년 전에 보고한 암 발생률과 현재의 발생률이 얼마나 차이가 있는가를 살펴 본 것으로 발생률의 변동이 연도별로 크게 차이가 나면 암등록의 충실성에 문제가 있다고 판단하는 것인데, 아직 $\mathrm{KCR}$ 은 4년 정도로 등록의 초창기에 있기 때문에 이 지표 의 산출이 불가능하였다.

셋째, $\mathrm{DCN}, \mathrm{DCO}$ 발견을 위해 역추적을 수행한 병원이 2 개의 종합병원에 국한된 점이다. 이것은 광주지역에서 암을 진단, 치료하는 다른 병원의 전산화가 빈약하여 등 록환자의 전체 등록 자료와 연결하기 어렵기 때문이지만, 실제 암으로 의료이용을 했음에도 불구하고 역추적 대상 에서 배제되었을 가능성이 있다.

\section{결 론}

1997 1998년, 광주광역시 지역 암등록에서 $\mathrm{DCO}$ 는 모 든 암 발생의 $12.2 \%$ 를 차지하였다. $\mathrm{DCO} \%$ 는 성별에 따른 차이는 적었고, 연령, 암 부위, 조직학적 확진율과 의사의 사망진단서 첨부 등에 의해 영향을 받는 것으로 나타났 다. 이러한 사실은 향후 $\mathrm{KCR}$ 의 $\mathrm{DCO} \%$ 를 낮추기 위하여 여러 가지 다양한 사회문화적 접근이 필요함을 시사하여 준다.

\section{참 고 문 헌}

1. Jensen OM, Parkin DM, MacLennan R, Muir CS, Skeet RG. Cancer Registration: Principles and Methods, Lyon; IARC Scientific Publications No. 95, 1991.

2. Kim IS. Epidemiological usefulness of registered death information in Korea. Korean J Epidemiol 1989;11:143-149.

3. Meng KH. Problems and improvement of mortality data in Korea. Korean J Epidemiol 1989;11:150-154.
4. Percy C, Stanek E 3d, Gloeckler L. Accuracy of cancer death certificates and its effect on cancer mortality statistics. Am J Public Health 1981;71:242-250.

5. Parkin DM, Chen VW, Ferlay J, Galceran J, Storm HH, Whelan SL. Comparability and quality control in cancer registration. Lyon; IARC Technical Report No: 19, 1994.

6. Parkin DM, Whelan SL, Ferlay J, Raymond L, Young J. Cancer Incidence in Five Continents. Vol VII. Lyon; IARC Scientific Publications No. 143, 1997.

7. Brenner H. Limitations of the death certificate only index as a measure of incompleteness of cancer registration. $\mathrm{Br} \mathrm{J}$ Cancer 1995;72:506-10.

8. Bullard J, Coleman MP, Robinson D, Lutz JM, Peto J. Completeness of cancer registration: A new method for routine use. Br J Cancer 2000;82:1111-1116.

9. Menck H, Smart C. Central cancer registries; design, management, and use. Harwood Academic Published GmbH 1994.

10. Ahn DH. Population-based Cancer Registry in Five Cities of Korea. 1998.

11. Ahn DH. Population-based Cancer Registry in Five Cities of Korea. 1999.

12. Choi JS, Sohn SJ, Na BJ, Sun BH, Park KS, Kweon SS, Im JS, Kim YJ, Hwang TJ. A feasibility study for the implementation of Kwangu Cancer Registry (KCR). J Korean Cancer Assoc 1999;3 1(4):749-757.

13. Pollock AM, Vickers N. Why are a quarter of all cancer deaths in south-east England registered by death certificate only? Factors related to death certificate only registrations in the Thames Cancer Registry between 1987 and 1989. Br J Cancer 1995; 1:637-64 1.

14. Vercelli M, Capocaccia R, Quaglia A, Casella C, Puppo A, Coebergh JWW, EUROCARE Working Group. Relative survival in elderly European cancer patients: Evidence for health care inequalities. Crit Rev Oncol Hematol 2000;35: 161-179.

15. Shin HR, Lee DH. Busan Cancer Registry. Ministry of Health and Welfare. 2000.

16. Chen VW, Wu XC, Andrews PA. Cancer in North America, 199 1-1995 Volume One: Incidence, North American Association of Central Cancer Registries, 1999.

17. Pollock AM, Vickers N. Reducing DCO registrations through electronic matching of cancer registry data and routine hospital data. Br J Cancer 2000;82:7 12-717.

18. Kwangju Metropolitan City. 1998 The Statistics of Registered Population. 1999.

19. Kwangju Metropolitan City. 1999 The Statistics of Registered Population. 2000.

20. Korean National Statistical Office. 1998 Annual Report on the Cause of Death Statistics. 1999.

21. Korean National Statistical Office. 1999 Annual Report on the Cause of Death Statistics. 2000.

22. Percy C, Van Holten V, Muir C. International Classification of Disease for Oncology. 2nd ed., Geneva; World Health Organization, 1990.

23. Esteban D, Whelan S, Laudico A, Parkin DM. Manual for Cancer Registry Personnel, Lyon; IARC Technical Report No. 10, 1995.

24. Seiffert JE. Standards for Cancer Registries Volume III, Standards for Completeness, Quality, Analysis, and Management of Data. American Association of Central Cancer Registries, 1994.

25. Gaudette L. Personal Communication. Letter to editor January 7, 1994. 